\title{
Improved sliding mode power control of doubly-fed-induction generator under wind speed variation
}

\author{
Bouiri Abdesselam', Benoudjafer Cherif ${ }^{2}$, Boughazi Othmane ${ }^{3}$, Abdallah Abden ${ }^{4}$, Chojaa Hamid \\ ${ }^{1-3}$ Laboratory of Smart Grids \& Renewable Energies (S.G.R.E), Department of Electrical Engineering, Bechar University, \\ Algeria \\ ${ }^{4}$ Control analysis and optimization of Electro-energy systems laboratory, Bechar University, Algeria \\ ${ }^{5}$ Laboratory of Technologies and Industrial Services, Higher School of Technology, USMBA University, Fez, Morocco
}

\begin{abstract}
Article Info
Article history:

Received Mar 24, 2020

Revised Sep 21, 2021

Accepted Sep 28, 2021

\section{Keywords:}

Chattering phenomenon

Doubly-fed-induction generator

Robustness

Sliding mode combining with

backstepping

Sliding mode controller

ABSTRACT

Due to drawbacks of classical linear controller like proportional-integral (PI), many studies have been used non-linear controller specially when it comes to robustness, but this is less efficient in sliding mode controller (SM) due to the sign function, this function is known as a problem chattering phenomenon, this main disadvantage it can be compensated by Lyapunov backstepping condition, This paper presents nonlinear power control strategy of the doubly-fed-induction generator (DFIG) for wind application system (WAS) using sliding mode combining with backstepping controller (SM-BS) to control produced statoric powers to mitigate unnecessary chattering effects inherent in traditional SMC, to check the effectiveness of the controller, we compare performance of sliding mode controller and sliding mode controller combining with backstepping (SM-BS) in terms of required reference tracking, robustness under parametric variations of the generator, sensitivity to perturbations and reaction to speed variations under investigating further of the chattering phenomenon.
\end{abstract}

Wind application system
This is an open access article under the $\underline{C C B Y-S A}$ license.

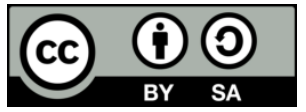

\section{Corresponding Author:}

Bouiri Abdesselam

Laboratory of Smart Grids and Renewable Energies (S.G.R.E)

Bechar University

B.P. 417 BECHAR, 08000, Algeria

Email: abdou.dwidi@gmail.com

\section{INTRODUCTION}

The use of renewable energy has become imperative in our time, not only use its but also develop and make optimal use of its, Among these energies are wind power, which is based on several types of generators, These generators include the doubly-fed induction generator (DFIG) which is the optimal solution used in wind application system for the variable speed [1] the WECS-based DFIG has many advantages high respond efficiency under wind speed variation the generator can work for $\pm 30 \%$ of synchronous speed, Less mechanical intricacy, decoupled controllable power, and a low cost rotor converter [2]. However, it is a challenge to control the DFIG since it presents a multivariable nonlinear and coupled system with many parameter uncertainties (resistance, inductance, inertia, friction coefficient). And in this case the use of PI controller is not very effective because of the limited robustness which is due to linearization function of DFIG by the addition of the term of compensation without adjustment, on the other, the non-linear control which takes all the function of the DFIG on consideration.

Many approaches and techniques, such as, the backstepping controller (BC) [3] and the sliding mode controller (SM) [4], have been proposed to deal provide fast transient response and handle parameter 
variations [5], show that the backstepping controller and have a good tracking and robustness performance. Moreover, despite the well admitted effectiveness and robustness of SMC strategies [6], several solutions to the chattering problem have been proposed for instance [7] proposes a new sliding surface giving rise to an integral sliding mode or sliding mode with double integral of. The obtained controller reduces the chattering phenomenon but fails to suppress it. And also, the second order sliding mode (2-SMC) was found to be a good solution for the chattering problem. Indeed, for different variant of the 2-SMC, that is, with the twisting algorithm, with the terminal algorithm or with the quasi-continuous algorithm, the chattering is eliminated, [8], these solutions prove effective in reducing the chattering and guarantying the system robustness, but tend to slow the system responses. In [9], a new method called multi-level switching technique has been proposed. This approach use variable switching gains to eliminate the chattering effect. The combination of fuzzy logic and SMC has been studied in [1], and sliding mode backstepping control [10] Previous work by the authors.

This article presents a new sliding mode controller (SMC) combining with backstepping (SM-BS) using Lyapunov conditions. For effective in reducing the chattering especially in the presence of PWM rotor converter (RSC) under wind variation speed where were we able to ensure system robustness, we check its effectiveness through a comparative study between tow controller classical sliding mode (SM), and which compensated by backstepping (SM-BS) in terms of reference power required, sensitivity to perturbations under wind speed variations, and robustness against parameters variations the results analyzed in MATLAB/Simulink software. This paper present firstly the modeling of DFIG, then we developed the control synthesis of output active and reactive powers using classical SM controller and then we improve its performance by addition of Lyapunov backstepping condition (SM-BS). Finally, by the results obtained we can confirm the efficiency of this hybrid control.

\section{MATHEMATICLA MODEL OF DFIG}

The Park frame model of DFIG can be represented by stator, rotor voltage and flux expressions as follows [11]-[13].

$$
\left\{\begin{array}{l}
v_{d s}=R_{s} i_{d s}+\frac{d \phi_{d s}}{d t}-w_{s} \phi_{q s} \\
v_{q s}=R_{s} i_{q s}+\frac{d \phi_{q s}}{d t}+w_{s} \phi_{d s} \\
v_{d r}=R_{r} i_{d r}+\frac{d \phi_{d r}}{d t}-w_{g} \phi_{q r} \\
v_{q r}=R_{r} i_{q r}+\frac{d \phi_{q r}}{d t}+w_{g} \phi_{d r}
\end{array}\right.
$$

where:

$$
\begin{gathered}
w_{g}=w_{s}-w_{r} \\
\left\{\begin{array}{l}
\phi_{d s}=L_{s} i_{d s}+M i_{d r} \\
\phi_{q s}=L_{s} i_{q s}+M i_{q r} \\
\phi_{d r}=L_{r} i_{d r}+M i_{d s} \\
\phi_{q r}=L_{r} i_{q r}+M i_{q s}
\end{array}\right.
\end{gathered}
$$

the stator active and reactive powers are written:

$$
\left\{\begin{array}{l}
p_{s}=v_{d s} i_{d s}+v_{q s} i_{q s} \\
Q_{s}=v_{q s} i_{d s}-v_{d s} i_{q s}
\end{array}\right.
$$

\section{THE NON-LINEAR STRATEGY OF CONTROL DFIG}

To regulate the DFIG, we use strategy that provides a decoupled between $d$-q reference frame by oriented statoric flux along the direct axis we have: $\phi_{d s}=\phi_{s}$ and $\phi_{q s}=0$. [13], and also by neglecting the statoric resistance $R_{S}=0$ under the premise of high generators with high power, under also the hypothesis of grid stability simple voltage $v_{s}$, it's leading to a constant stator flux $\phi_{s}$. We obtained: $v_{d s}=0 v_{q s}=V_{s}$ and we can control the output active and reactive powers of DFIG through the control of rotor current (5) can be written: 


$$
\left\{\begin{array}{l}
p_{s}=\frac{-M V_{s}}{L_{s}} i_{q r} \\
Q_{s}=\frac{-M V_{s}}{L_{s}} i_{d r}+\frac{V_{s}^{2}}{w_{s} L_{s}}
\end{array}\right.
$$

The input reference voltages of DFIG expressed as follows:

$$
\left\{\begin{array}{l}
v_{q r}=R_{r} i_{q r}+\delta \frac{d i_{q r}}{d t}+w_{g} \delta \cdot i_{d r}+\frac{g M v_{s}}{L_{s}} \\
v_{d r}=R_{r} i_{d r}+\delta \frac{d i_{d r}}{d t}-w_{g} \delta \cdot i_{q r}
\end{array}\right.
$$

Where $\delta=L_{r}-\frac{M^{2}}{L_{s}}$ is the coupling term, and the slip is, $g=\left(w_{s}-w_{r}\right) / w_{r}$

\section{SLIDING MODE CONTROLLER SYNTHESIS}

The basic concept of sliding mode is to bringing he state trajectory back closer to the sliding surface and step forward with a certain dynamic equilibrium point [14]-[16]. We take the form of the general equation proposed by Slotine and Li to find the sliding mode surface [17]:

$$
\left\{\begin{array}{c}
s(x)-\left(\frac{d}{d t}+\delta\right)^{N-1} e(x) \\
e(x)-X^{s}-X
\end{array}\right.
$$

where e is the sliding mode surface to be adjusted, $\delta$ is the positive coefficient, $\mathrm{n}$ is the system order, $X=$ $\left[x, \dot{x} \ldots, x^{n-1}\right]^{T}$

variable of the reference signal, an $X^{d}=\left[x^{d}, \dot{x}^{d} \ldots, x^{(n-1)^{d}}\right]^{T}$, It's the controller signal. The structure of a controller has two main functions; for the linearization and stabilizing [18] this last is very necessary in terms of control by means of sliding technique, because it is used to reject external disturbances; The control algorithm determines through the relationship:

$$
U(t)=U e q(t)+U n(t)
$$

Ueq $(t)$ The Filipov and Utkin proposal for the equivalent function [19]. This is used to preserve the sliding surface condition $(V(t)=0)$ calculated by acknowledging that behavior of the system during the sliding mode can give by:

$$
\dot{S}(x)=0
$$

Convergence condition

$U n(t)$ The dynamic behavior of the system during the convergence condition is calculated in order to satisfy the conditions of convergence, to ensure the attractiveness of the variable to control the sliding surface:

$$
\dot{S(x)}=\operatorname{Un}(t)
$$

we select the error between measured and referenced stator forces in our study as sliding mode surfaces with an $\mathrm{n}=1$.

$$
\left\{\begin{array}{l}
S(P)=P_{s_{r} r e f}-P_{S} \\
S(Q)=Q_{s_{-} r e f}-Q_{S}
\end{array}\right.
$$

By deriving sliding surfaces and using powers (5) then we shoot the current expression $\dot{i_{q r}}$ and $\dot{i_{d r}}$ from voltage (6) is obtained:

$$
\left\{\begin{array}{l}
\dot{S(P)}=P_{s_{-} r e f}+\frac{M V_{s}}{L_{s} \delta}\left[V_{q r}-R_{r} i_{q r}-w_{g} \delta \cdot i_{d r}-\frac{g M V_{s}}{L_{s}}\right] \\
\dot{S} \dot{Q})=Q_{s_{-} r e f}+\frac{M V_{s}}{L_{s} \delta}\left[V_{d r}-R_{r} i_{d r}+w_{g} \delta \cdot i_{q r}\right]
\end{array}\right.
$$

by replacing the expression of $V_{q r}$ and $V_{d r}$ by $\left(V_{q r}{ }^{e q}+V_{q r}{ }^{n}\right)$ and $\left(V_{d r}{ }^{e q}+V_{d r}{ }^{n}\right)$ respectively, 


$$
\left\{\begin{array}{l}
\dot{S(P)}=P_{s_{-} r e f}+\frac{M V_{s}}{L_{s} \delta}\left[\left(V_{q r}^{e q}+V_{q r}{ }^{n}\right)-R_{r} i_{q r}-w_{g} \delta \cdot i_{d r}-\frac{g M V_{s}}{L_{s}}\right] \\
\dot{S(Q)}=Q_{s_{-} r e f}+\frac{M V_{s}}{L_{s} \delta}\left[\left(V_{d r}^{e q}+V_{d r}{ }^{n}\right)-R_{r} i_{d r}+w_{g} \delta \cdot i_{q r}\right]
\end{array}\right.
$$

In sliding mode steady state condition, $=0$ the controls $V_{q r}{ }^{n}=V_{d r}{ }^{n}$ and $\dot{S(P)}=0, \dot{S}(Q)=0$ equivalent is found from (13) written as follows:

$$
\left\{\begin{array}{l}
V_{q r}{ }^{e q}=\frac{-L_{s} \delta}{M V_{s}} P_{S_{-} r e f}+R_{r} i_{q r}+w_{g} \delta \cdot i_{d r}+\frac{g M V_{s}}{L_{S}} \\
V_{d r}{ }^{e q}=\frac{-L_{s} \delta}{M V_{s}} Q_{s_{-} r e f}+R_{r} i_{d r}-w_{g} \delta \cdot i_{q r}
\end{array}\right.
$$

Substituting the expression (14) in (13), And the following expression can be written:

$$
\left\{\begin{array}{l}
\dot{S(P)}=\frac{M V_{s}}{L_{s} \delta} V_{q r}{ }^{n} \\
\dot{S(Q)}=\frac{M V_{s}}{L_{s} \delta} V_{d r}{ }^{n}
\end{array}\right.
$$

To ensure the convergence of function $\dot{S(x)} . S(x) \prec 0$ accordingly, the switching terms are as follows:

$$
\left\{\begin{array}{l}
V_{q r}{ }^{n}=K_{V q r} . \operatorname{Sat}\left(S\left(P_{S}\right)\right) \\
V_{d r}{ }^{n}=K_{V d r} \cdot \operatorname{Sat}\left(S\left(Q_{s}\right)\right)
\end{array}\right.
$$

$K_{V q r}, K_{V d r}$ Positive parameters must be used to check system stability.

The classical sliding mode (SM) block diagram control for DFIG is shown in Figure 1. Note that the error function, sliding surface in Figure 1, is only included in the chatter function $\operatorname{Un}(t)$ for processing and does not input in equivalent function.

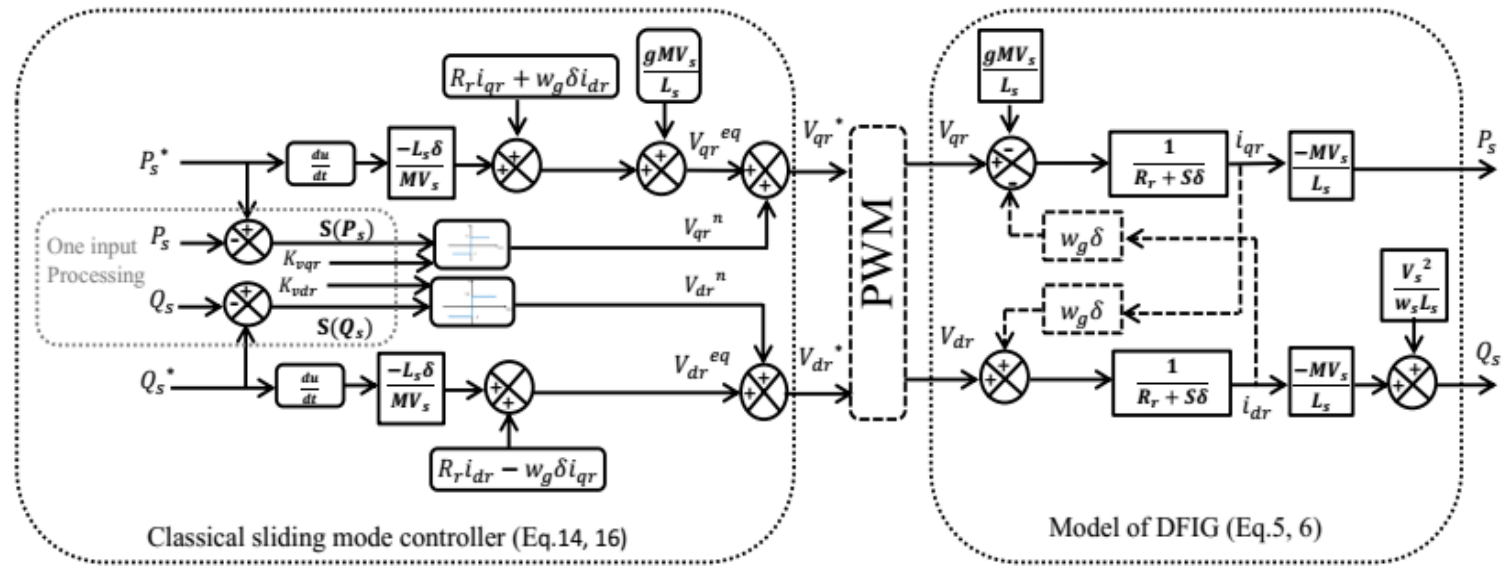

Figure 1. Classical sliding mode (SM) block diagram for DFIG

\section{SLIDING MODE COMBINING WITH BACKSTEPPING DESING}

Authors in[20]-[22] implemented the backstepping method in 1990 to maintain general consistency, usually multivariate to higher order, control systems. It is a method for synthesizing recursive classes of nonlinear triangular structures, whatever their order [23]. Backstepping technique is a nonlinear method for control multivariable system on the basis of the Lyapunov theorem [24]. Compared with other control methods, [25] backstepping advantage is its versatility that is appropriate for any variation to keep condition stability of the system.

We choose the Lyapunov V1 function first in a quadratic form for our system

$$
V_{1}=\frac{1}{2} e_{1}^{2}
$$


The derivative is as follows:

$$
\dot{V}_{1}=e_{1} \cdot \dot{e_{1}}
$$

Lyapunov condition to guarantee the stability of the subsystem $\dot{V}_{1}$, must be negative so we have to choose:

$$
\dot{V}_{1}=-k \cdot e_{1}{ }^{2}<0
$$

we base on (19) to check the stability condition with the sign function of the classical SM controller for the condition. The condition of convergence $S(x) . S(x) \prec 0$ can be verified by the use of the equation of lyaponov backstepping condition (19) directly in the (13):

$$
\left\{\begin{array}{l}
\dot{S}\left(P_{s}\right)=P_{s_{-} r e f}+\frac{M V_{s}}{L_{s} \delta}\left[\left(V_{q r}^{e q}+V_{q r}{ }^{n}\right)-R_{r} i_{q r}-w_{g} \delta . i_{d r}-\frac{g M V_{s}}{L_{s}}\right]=-K_{1} S\left(P_{s}\right) \\
\left.\dot{\dot{Q}} \dot{Q}_{s}\right)=\dot{Q}_{s_{-} r e f}+\frac{M V_{s}}{L_{s} \delta}\left[\left(V_{d r}{ }^{e q}+V_{d r}{ }^{n}\right)-R_{r} i_{d r}+w_{g} \delta . i_{q r}\right]=-K_{2} S\left(Q_{s}\right)
\end{array}\right.
$$

$k_{1}, k_{2}>0$ active and reactive powers Gain of respective.

During sliding steady state condition, $\dot{S(P)}=0, \dot{S}(Q)=0$ and $V_{q r}{ }^{n}=V_{d r}{ }^{n}=0$ equivalent function are found from (20) written as follows:

$$
\left\{\begin{array}{l}
V_{q r}{ }^{e q}=\frac{-L_{s} \delta}{M V_{s}} P_{s_{-} r e f}+R_{r} i_{q r}+w_{g} \delta . i_{d r}+\frac{g M V_{s}}{L_{s}}+\frac{-L_{s} \delta}{M V_{s}} K_{1} S\left(P_{S}\right) \\
V_{d r}{ }^{e q}=\frac{-L_{s} \delta}{M V_{s}} Q_{s_{-} r e f}+R_{r} i_{d r}-w_{g} \delta \cdot i_{q r}+\frac{-L_{s} \delta}{M V_{s}} K_{2} S\left(Q_{s}\right)
\end{array}\right.
$$

Substituting the expression (21) in (20), same way in (15) and (16) for find the expression of $V_{q r}{ }^{n}, V_{d r}{ }^{n}$ with the same values of SM $\left(K_{V q r}, K_{V d r}\right)$ for ensure the performance of the new controller (SM-BS) Thus, the diagram block of Sliding mode combining with backstepping control of the DFIG is shown in the Figure 2.

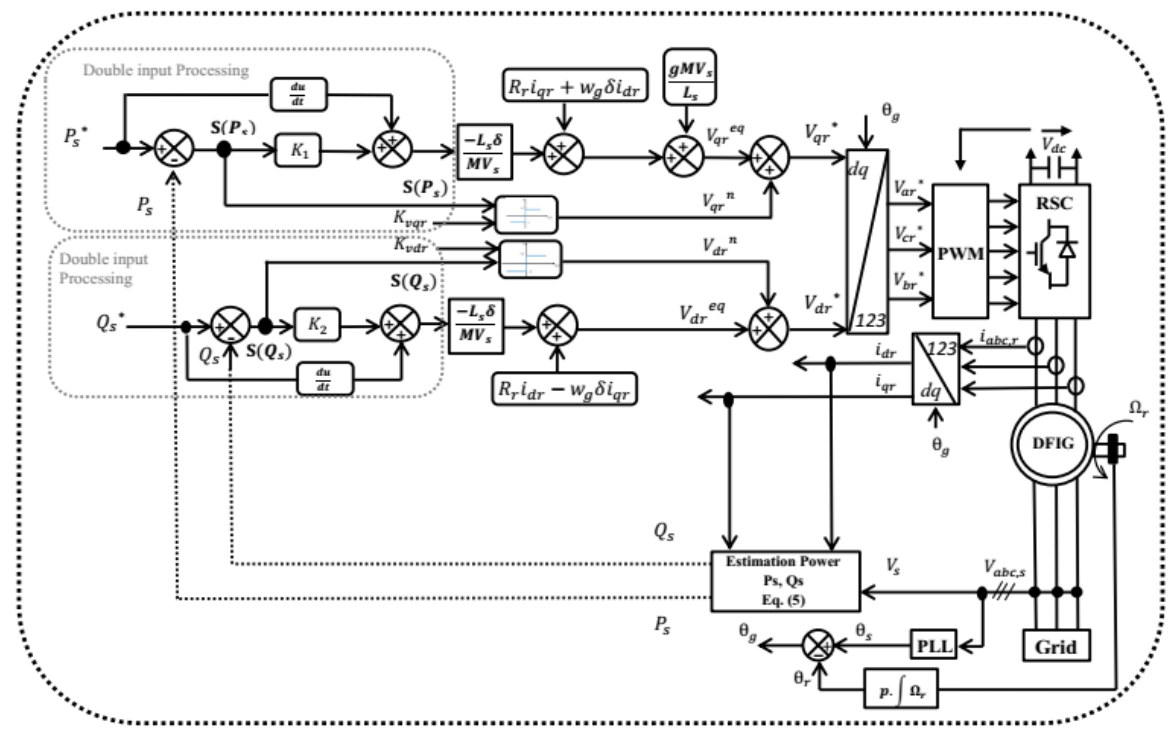

Figure 2. DFIG diagram block of Sliding mode combining with backstepping

\section{SIMULATION RESULTS}

\subsection{Tracking test}

The active and reactive response of the DFIG $(5 \mathrm{KW})$ by tow regulators (SM, SM-BS) without PWM converter (level two) and without perturbations (At the nominal speed of the generator.) and no parameters variations for the track test. Where we noticed the close performance of the regulators with improvement of the SM-BS controller shown in Figure 3. 

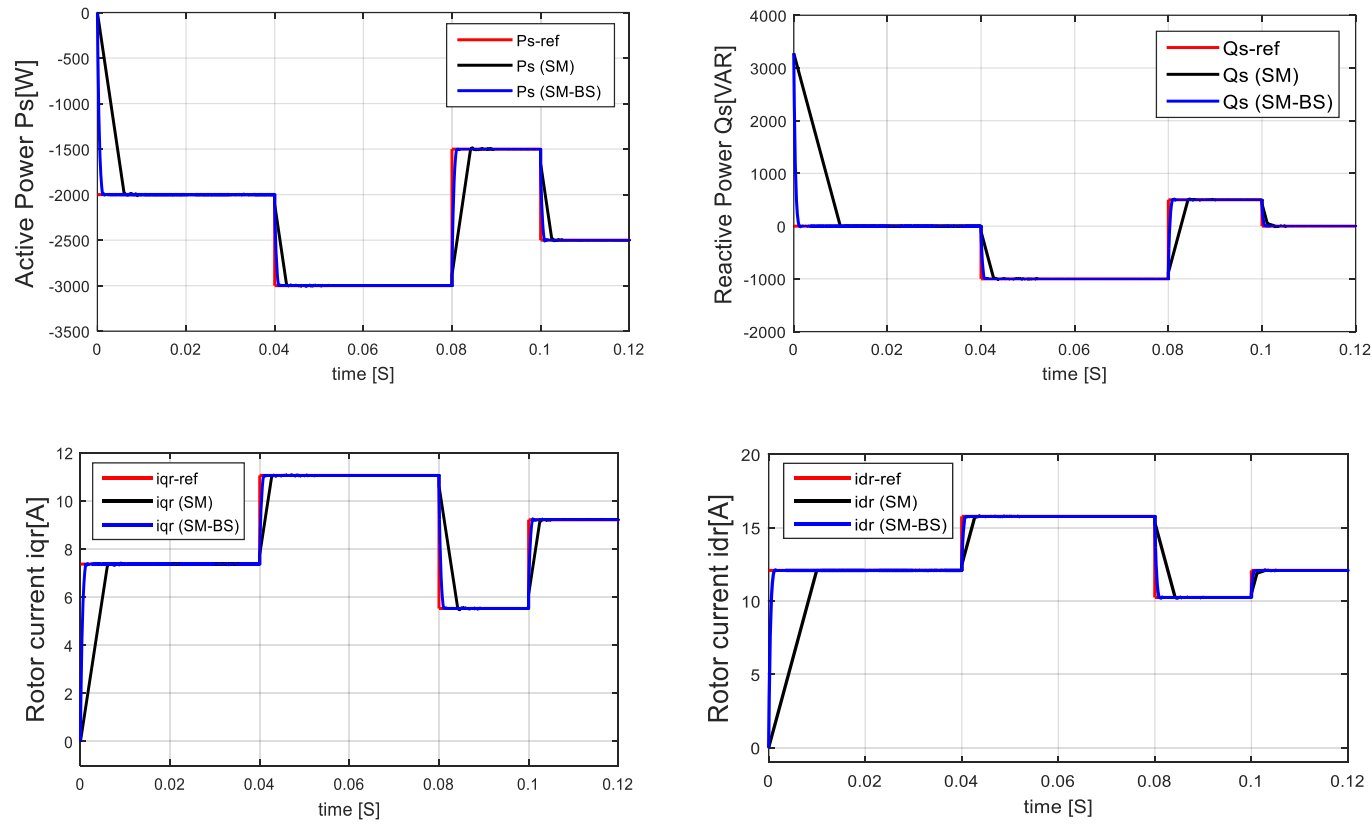

Figure 3. Power/current controller response of DFIG (reference test)

\subsection{Robustness tests}

The robustness test against parameters variations of DFIG. Figure 4 the value of the rotoric and statoric inductance $L_{r}$ and the magnetizing inductance $\mathrm{M}$ are increased by $50 \%$ and $10 \%$ successively of the nominal values, the rotoric resistance $R_{r}$ is increased by $100 \%$ of nominal value.
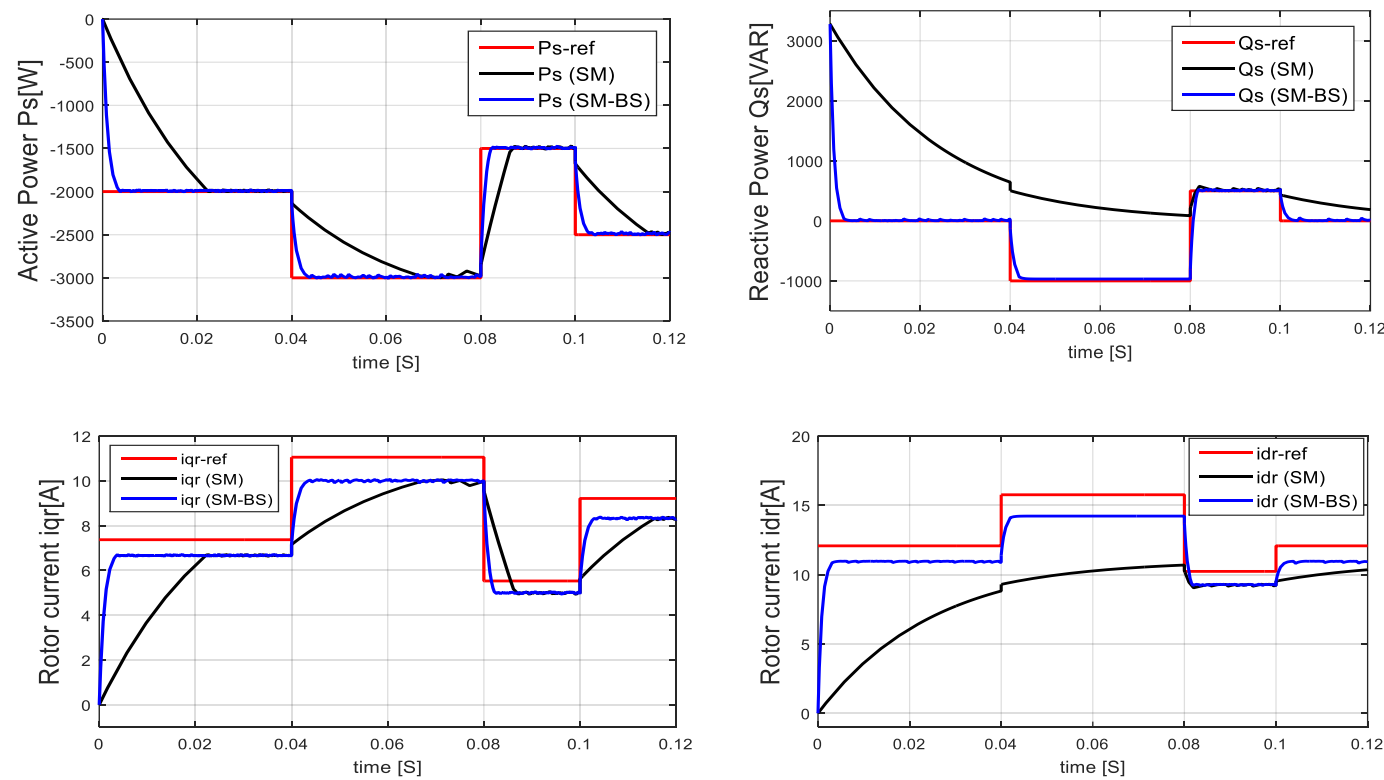

Figure 4. Controller response of DFIG $\left(L_{r},+50 \%, M+10 \%, R_{r}+100 \%\right)$

\subsection{Sensitivity to Perturbations test: (chattering phenomenon)}

It is clearly shown Figure 5 with PWM, the dramatic amplitude reduction of the oxillations concerning chattering phenomenon and almost zero error reference tracking in the case sliding modbackstepping (SM-BS) control. Under speed variation at $\mathrm{t}=2 \mathrm{~s}$. 

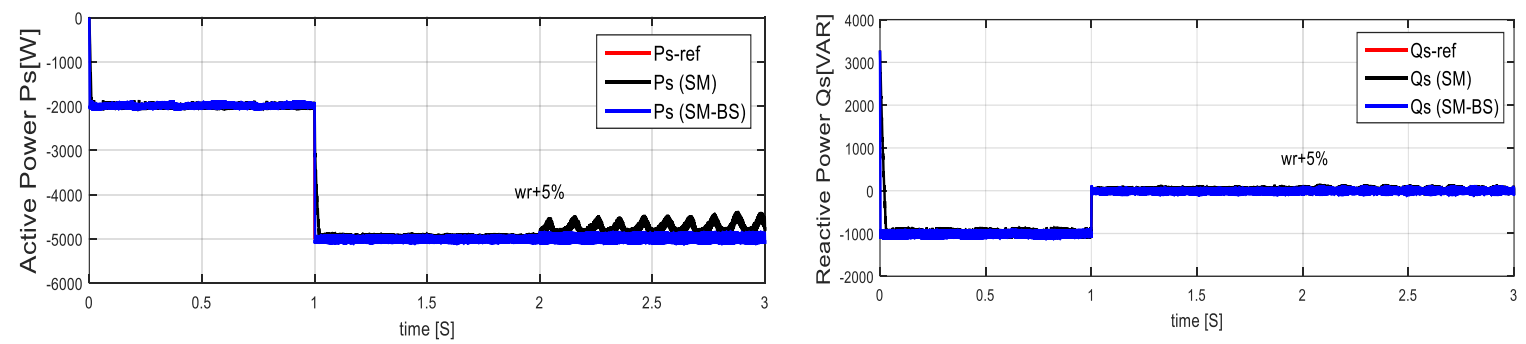

Figure 5. Controller response of DFIG under wind speed variation (Chattering phenomenon)

\section{CONCLUSION}

In this paper we have been able to make the sliding surface (error) as input function for both main functions (Veq and Vn) of SM-BS with four setting gain (Kvdr; Kvqr; K1, K2), reverse conventional SM control has one input of sliding surface only about sign function and this is the main drawback. This combined control between sliding mode and backstepping technique, created a new control added to the classical sliding mode, it gave good results after the comparative study between SMC and SM-BS: after the results obtained by MATLAB/Simulink, for this new controller we can observe High output response time for tracking of references and it's more robust against parameters variation of the DFIG versus the conventional SM controller. And regarding chattering phenomenon and sensitivity to perturbation, we also observe elimination of the chattering phenomenon the effect of the PWM clearly decreases and with its high efficiency to maintain its performance in the presence of perturbation (speed variation $t=2 \mathrm{~s}$ ) compared to the classical SM controller.

\section{REFERENCES}

[1] S. Labdai, N. Bounar, A. Boulkroune, and B. Hemici, "Sliding mode control via fuzzy multi-level switching control scheme for DFIG based WECS," in Romanian Journal of Information Science and Technology, vol. 21, no. 4, pp. 429-445 21, 2018.

[2] S. El Aimani, "Modeling of various wind turbine technologies integrated in medium voltage networks (in French)," Thesis, l'université lille 1 - sciences et technologies. 2004.

[3] H. El Fadil, and F. Giri, "Backstepping based control of pwm DC-DC boost power converters," 2007 IEEE International Symposium on Industrial Electronics, 2007, pp. 395-400, doi: 10.1109/ISIE.2007.4374630.

[4] Y. Massaoudi, D. Elleuch, D. Mehdi, T. Damak and G. Hashim, "Comparison between nonlinear controllers applied to a DC-DC boost converter," International Journal of Innovative Computing, Information and Control vol. 11, no. 3, pp. 935-947, 2015.

[5] Y. Massaoudi, D. Elleuch, J. Gaubert, and T. Damak, "A new backstepping sliding mode controller applied to a DC-DC boost converter," International Journal of Power Electronics and Drive Systems (IJPEDS), vol. 7, no. 3, pp. 759-768, 2016, doi: 10.11591/ijpeds.v7.i3.pp759-768.

[6] S. Verma, S. K Singh, and A. G. Rao, "Overview of control techniques for DC-DC converters," Research Journal of Engineering Sciences, vol. 2, no. 8, pp. 18-21, 2013.

[7] F. Harirchi, A. Rahmati, and A. Abrishamifar, "Boost PFC converters with integral and double integral sliding mode control," 19th Iranian Conference on Electrical Engineering (ICEE), 2011, pp. 1-6.

[8] D. Elleuch, and T. Damak, "Backstepping sliding mode controller coupled to adaptive sliding mode observer for interconnected fractional nonlinear system," International Journal of Mechanical and Mechatronics Engineering, vol. 7, no. 3, pp. 372-378, 2013, doi: 10.5281/zenodo.1057065.

[9] S. Sutha, P. Lakshmi, S. Sankaranarayanan, and H. A. Shabeer, "Improved robustness and finite time convergence for a multivariable process using integral terminal sliding mode controller via multi-level switching," Journal of Scientific and Industrial Research, vol. 74, no. 8, pp. 444-449, 2015.

[10] O. Boughazi, A. Boumedienne, and H. Glaoui, "Sliding mode backstepping control of induction motor," in International Journal of Power Electronics and Drive System (IJPEDS), vol. 4, no. 4, pp. 481-488, 2014, doi: 10.11591/ijpeds.v4.i4.pp481-488.

[11] G. Abad, J. López, M. Rodríguez, L. Marroyo, and G. Iwanski, Doubly Fed Induction Machine Modeling and Control for Wind Energy Generation, Wiley-IEEE Press, 2011.

[12] M. Loucif, A. Boumediene, and A. Mechernene, "Backstepping control of double fed induction generator driven by wind turbine," 3rd International Conference on Systems and Control, 2013, pp. 153-158, doi: 10.1109/ICoSC.2013.6750851.

[13] B. Ouamri, and Z. F. Ahmed, "Comparative analysis of robust controller based on classical proportional-approach for power control of wind energy system," in Rev. Roum. Sci. Techn.-Électrotechn. et Énerg., vol. 63, no. 2, pp. 210-216, Bucarest, 2018.

[14] J.J.E. Slotine, and W. Li, Applied nonlinear control, Prentice-Hall, Inc., USA, 1998. 
[15] S. Muller, M. Deicke, and R.W. De Doncker, "Doubly fed induction generator systems for wind turbines," IEEE Industry Applications Magazine, vol. 8, no. 3, pp. 26-33, 2002, doi: 10.1109/2943.999610.

[16] V. I. Utkin, "Sliding mode control design principles and applications to electric drives," IEEE Trans. Ind. Electronics, vol. 40, no. 1, pp. 23-36, 1993, doi: 10.1109/41.184818.

[17] J. Hu, H. Nian, B. Hu, Y. He, and Z. Q. Zhu, "Direct active and reactive power regulation of DFIG using slidingmode control approach," IEEE Transactions on Energy Conversion, vol. 25, no. 4, pp. 1028-1039, 2010, doi: 10.1109/TEC.2010.2048754.

[18] M. Itsaso Martinez, A. Susperregui, G. Tapia, and H. Camblong, "Sliding-mode control for a DFIG-based wind turbine under unbalanced voltage," Proceedings of the 18th World Congress the International Federation of Automatic Control Milano (Italy) August 28 - September 2, 2011, doi: 10.3182/20110828-6-IT-1002.00854.

[19] A. M. Kassem, K. M. Hasaneen, and A. M. Yousef, "Dynamic modeling and robust power control of DFIG driven by wind turbine at infinite grid," International Journal of Electrical Power \& Energy Systems, vol. 44, no. 1, pp. 375-382, January 2013, doi: 10.1016/j.ijepes.2011.06.038.

[20] M. Krstic, I. Kanellakopoulos, and P. V. Kokotovic, "Nonlinear design of adaptive controllers for linear systems," IEEE Transactions on Automatic Control, vol. 39, no. 4, pp. 738-752, April 1994, doi: 10.1109/9.286250.

[21] M. Krstic, I. Kanellakopoulos, and P.V. Kokotovic, Nonlinear and Adaptive Control Design, Wiley, New York, 1995.

[22] M. Ariffanan M. Basri, and A. Rashid Husain, "Robust chattering free backstepping sliding mode control strategy for autonomous quad rotor helicopter," in International Journal of Mechanical \& Mechatronics Engineering IJMME-IJENS, vol. 14, no. 3, pp. 375-382, 2013, doi: 10.1016/j.ijepes.2011.06.038.

[23] N. Khemiri, A. Khedher, and M.F. Mimouni, "An adaptive nonlinear backstepping control of DFIG driven by wind turbine," WSEAS Transactions on Environment and Developmen, vol. 8, no. 2, April 2012.

[24] M. Doumi, A.G. Aissaoui, A. Tahour, M. Abid, and K. Tahir, "Nonlinear backstepping control of a double-fed induction generator," International Conference on Renewable Energy Research and Application, Palermo 22-25 Nov, 2015, doi: 10.1109/ICRERA.2015.7418495.

[25] M. Doumi, A. Aissaoui, A. Tahour, M. Abid, and K. Tahir, "Nonlinear integral backstepping control of wind energy conversion system based on a double-fed induction generator," Przeglad Elektrotechniczny, vol. 1, no. 3, pp. 132-137, 2016, doi: 10.15199/48.2016.03.32. 